The Canadian Journal of Higher Education, Vol. XXIII-2, 1993

La revue canadienne d'enseignement supérieur, Vol. XXIII-2, 1993

\title{
Logistic Regression Analysis of Graduate Student Retention
}

\section{SANDRA W. PYKE ${ }^{*} \&$ PETER M. SHERIDAN ${ }^{\dagger}$}

\begin{abstract}
Logistic regression analysis was utilized to predict the retention of 477 master's and 124 doctoral candidates at a large Canadian university. Selected demographic (e.g., sex, marital status, age, citizenship), academic (e.g.. GPA, discipline, type of study, time to degree completion) and financial support variables (e.g., funding received from internal and external scholarships and from research, graduate and teaching assistantships) were used as independent variables. The dichotomous dependent variable was whether the student successfully completed the degree. Results for master's students indicate that higher graduate GPAs, increased length of time in the program, increased funding from all sources, full- or part-time registration status in the coursework only program, and full-time registration status in the coursework plus major research paper program significantly improve the student's chances of graduating with the degree. For doctoral candidates, only increased length of time in the program and increased funding from all sources significantly increase the chances of graduating with the doctorate.
\end{abstract}

\section{Résumé}

Dans une grande université canadienne, on a eu recours à l'analyse logistique de régression pour calculer le taux de rétention de 477 candidats de maîtrise et 124 de doctorat. Un certain nombre de variables - démographiques (par ex., le sexe,

* Dean, Faculty of Graduate Studies; Professor, Department of Psychology, York University.

$\dagger$ Graduate Program in Psychology. York University. 
le statut matrimonial, l'âge, la citoyenneté), académiques (par ex., la moyenne générale, la discipline, le type d'études, le temps mis pour obtenir le diplôme) et d'aide financière (par ex., les bourses d'études internes et externes, celles d'assistant de recherche et d'enseignement) ont été utilisées comme variables indépendantes. Comme variable dépendante dichotomique, on a pris la réussite au diplôme. Pour les étudiants de maîtrise, les résultats obtenus indiquent qu'une moyenne générale élevée, un temps plus long passé dans le programme, une aide financière plus importante, ainsi qu'un statut d'étudiant(e) à plein temps ou à temps partiel dans un programme ne comportant que la scolarité, et un statut d'étudiant(e) à plein temps dans un programme où la scolarité s'accompagne d'un travail de recherche important, constituaient des facteurs qui augmentaient d'une manière significative les chances d'obtention du diplôme. Pour les étudiants de doctorat, les seuls facteurs augmentant d'une manière significative les chances d'obtention du diplôme étaient une augmentation du temps passé dans le programme et une augmentation de l'aides financière.

\section{Introduction}

Despite extensive investigation of the factors pertaining to student attrition (see reviews by Pantages \& Creedon, 1978; Tinto, 1975, 1987) and empirical validation of Tinto's (1987) theoretical model at the undergraduate level (Munro, 1981; Pascarella \& Chapman, 1983; Pascarella \& Terenzini, 1983; Stage, 1989 a 1989 b), relatively few studies have focused on student attrition at the graduate level (Berg \& Ferber, 1983; Girves \& Wemmerus, 1988; Naylor \& Sanford, 1982; Ott, Markewich \& Ochsner, 1984). Typically, the emphasis in the literature has been directed to investigating variables related to attracting the best and/or the under-represented students to graduate school (cf. Malaney, 1984) or to the length of time taken to complete graduate degree requirements (cf. Tuckman, Coyle \& Bae, 1989, 1990).

Analysis of graduate student attrition data is of particular interest to educational researchers and university administrators. Recent figures suggest that as many as $20 \%$ of master's students (Sheinin, 1989) and $48 \%$ of doctoral students (Duggan, 1989) fail to complete their degrees. Given forecasted faculty shortages, an understanding and amelioration of graduate student attrition has direct relevance to replacement of the professorate. As noted in a 1991 report of the Association of Universities and Colleges of Canada, "For the period 1990 to 2000 , annual faculty requirements are projected to increase faster than the number of Ph.D. graduates" (p. i). 
Atrition data are also cause for concern because of the impact of student attrition on institutional operations and financing. The dropout represents an unrecouped loss to the university in relation to the costs of admission, planning and running programs. and lost income in the form of refunded tuition and government financing, which in some jurisdictions is based on enrollment (Calder, McKay \& Nelson, 1977; Pascal \& Kanowitch, 1979). The student who eventually withdraws from the university may be absorbing financial support resources to the detriment of incoming students. If competitive funding for firstclass students is jeopardized in this manner, the overall quality of the incoming student cohort may be diluted.

Large numbers of withdrawing students may have adverse repercussions on the reputation of the university. A high attrition rate may be perceived by both future students and the general public to be a reflection of the university's inability to meet student needs, particularly career needs (Calder et al., 1977; Pascal \& Kanowitch, 1979). Although vocational training is not perceived to be one of the primary functions of a university, both those who finance and those who attend university are increasingly evaluating it in terms of its ability to produce marketable human resources.

Other effects of dropping out may be more difficult to gauge in the absence of long-term follow-up data. Certainly there will have been a heavy investment of resources without any tangible return, at least in the form of conferral of a degree. The process of withdrawal for the student may be a very painful experience, representing not only a loss of money and time, but also frustrated ambitions, unfulfilled goals, peer-group rejection, and feelings of self-doubt, disappointment and depression (Cope \& Hannah, 1975).

Rogers and Gentemann (1989) report, in their survey of 167 institutions of higher education in the United States, an alarming lack of preparedness on the part of colleges and universities to demonstrate their educational effectiveness empirically. While studies of student attrition represent only one possible index of institutional effectiveness, a critical first step towards the development of institutional assessment procedures is to define and examine expected educational outcomes. Although the vast majority of university administrators support the requirement of such efforts (El-Khawas, 1987), the findings of Rogers and Gentemann suggest that very few institutions are actively responding to the need for this type of information (cf. Pascal \& Kanowitch, 1979).

With the recent increase in demand for graduate education and a concomitant relative decrease in the provision of financial resources from federal and provincial governments, student attrition has become one area of increasing 
concern for university administrators anxious to determine the nature and extent of student loss and to develop strategies to maximize graduation rates. Administrators are eager to learn why some students with ostensibly reasonable credentials fail to obtain their degrees - because they withdraw voluntarily, or they are asked to withdraw as a result of poor academic performance, or they fail to complete degree requirements within the time limits specified by university regulations. By examining graduate student attrition, the present investigation is an attempt to respond to some of these important questions while simultaneously addressing the need for data on program effectiveness. Using logistic regression analysis to predict student retention, a number of variables can be identified which will allow university administrators to consider interventions to maximize completion rates in graduate programs.

\section{Method}

\section{Subjects}

A simple random selection process was utilized to identify a sample of 698 graduate students admitted to various disciplines at York University between January 1, 1975 and December 31, 1985. As all disciplines have either one- or two-year master's (M.A. and M.Sc.) degree programs, the selection of this tenyear cohort allowed the investigators to assess attrition across a series of master's classes. In addition, it was expected that the ten-year period of the investigation would allow sufficient time for all doctoral (Ph.D.) candidates beginning in January, 1975 to have either withdrawn or have had their degrees conferred by December, 1985. All data were derived from archival records maintained by the university.

Students from graduate programs in three discipline areas, natural sciences, social sciences and humanities. were included in this investigation. Natural science disciplines included biology, chemistry, mathematics and physics; social science disciplines included economics, exercise and sports science, geography, political science, psychology, social and political thought, social anthropology and sociology; and humanities disciplines included art history, English, history and philosophy.

The 698 graduate students in the identification sample included 539 master's students and 159 doctoral students. For the logistic regression procedures, sixty-two master's and 35 doctoral candidates were eliminated because of missing data, leaving final samples of 477 master's students and 124 Ph.D. students for those analyses. 


\section{Variables}

The selection of variables for the present investigation was determined primarily by the level of support they had received in the literature on undergraduate and graduate student retention (Sheridan, 1990). A secondary consideration was that the variables be available in relatively standardized form to ensure reliable retrieval from the archival record system. Twenty-one variables were selected for investigation as follows.

Demographic variables. These included sex, marital status, age, the square of the student's age and citizenship status. The age-squared variable was included to allow for the possibility that the relationship between age and degree progress might be nonlinear; the quadratic term was therefore made available to the regression equation in case an adequate accounting for age should require it. Citizenship status comprised three levels: Canadian, landed immigrant or foreign citizen.

Academic variables. These included the undergraduate and graduate grade point averages (GPAs) of the student, the student's discipline area, the type of study chosen, whether the student had ever taken a leave of absence and the length of time to degree completion.

Undergraduate GPA was calculated as the average of the student's grades in the final two years of undergraduate study; the graduate GPA of the student was calculated as the weighted (half- or full-course equivalents) average of the student's grades in the master's or doctoral years.

The student's discipline area was classified as natural sciences, social sciences. or humanities. The type of study variable was defined separately for master's and doctoral students. For master's students, this variable incorporated both the course of study chosen by the student (coursework only, coursework plus a major research paper or coursework plus a thesis) as well as the student's registration status (part- or full-time) and was, therefore, a categorical variable with six levels. This combination of variables was chosen as preliminary analyses suggested that there was no simple main effect of course of study or registration status when other variables were statistically controlled. At the Ph.D. level, the type of study variable reflected only part- or full-time registration status as the type of program for students at this level is uniform across discipline areas (coursework plus a dissertation). Since graduate students frequently move from full- to part-time status once residency requirements are met, determination of status was based on the student's initial registration as either a full- or part-time student. 
Whether the student had ever taken a leave of absence (LOA) during the time spent in the master's or doctoral program was coded dichotomously. Finally, the length of time spent in the program was computed as the time elapsed between the date of first registration in the master's or doctoral program and the date of conferral of the degree (and thus included time spent on LOAs).

Einancial variables. These included type and amount of funding from nine different sources as well as the average amount of funding from all sources. Funding sources considered were internal scholarships, research, graduate and teaching assistantships (RAs, GAs and TAs), Ontario Graduate Scholarships (OGS), fellowships granted by the Social Sciences and Humanities Research Council (SSHRC), the National Science and Engineering Research Council (NSERC) and the Medical Research Council (MRC), as well as a miscellaneous category including various other grants and scholarships.

To accommodate variability in program regulations relevant to student support (e.g., teaching assistantships were not permitted for master's students in some disciplines), to minimize variation in levels of support across programs and years, and to avoid a time confound. the predictor employed was an averaged amount of funding from each source over the student's participation in the graduate program. Monetary values (considered across students by year) were transformed into z-scores. The standardized scores were then averaged across an individual student's "history" in the graduate degree program to produce the "profile" of that student's earnings in each of the financial categories.

Lneraction terms. As recommended by Hosmer and Lemeshow (1989), interaction terms used were chosen on the basis of interpretability, logic, and support received in the literature. Three interaction terms were computed: sex by marital status, sex by type of study and marital status by type of study.

Dependent variable. Separate logistic regression analyses were carried out for master's and doctoral students. In both cases, the dichotomously coded dependent variable was whether or not the student had received his or her degree.

\section{Logistic Regression Analysis}

When the dependent variable in an attrition study is dichotomous (i.e., degree earned vs not earned), logistic regression, as opposed to either multiple regression or discriminant analysis, is particularly appropriate (Hosmer \& Lemeshow, 1989; SPSS, 1989). Like multiple regression, logistic regression analysis can be used to determine which independent variables and interactions are required to describe satisfactorily attrition or retention. Logistic regression analysis also provides predicted probabilities of retention for combinations of the independent variables. 
Although logistic regression is particularly useful in providing a parsimonious combination of the best predictor variables, such a procedure has the tendency to capitalize on chance sample characteristics (Kerlinger \& Pedhazur, 1973). The set of predictors yielded by one sample may not hold for another sample. It is therefore considered desirable when employing this procedure to correct for capitalizing on chance by cross-replicating to a new sample. A second random selection procedure was therefore utilized to divide both the master's and doctoral samples into two components, calibration samples and validation samples. All statistical analyses were conducted on the calibration samples. The regression equations derived from the calibration samples were then used to classify persisters and withdrawers in the calibration and validation samples.

The logistic regression procedure utilized (SPSS, 1989) automatically creates new variables for categorical variables. This obviates the necessity of creating "dummy variables" as in multiple linear regression (Lewis-Beck, 1980). In the present study, the coding scheme utilized for the creation of new variables was indicator coding. With indicator coding, the coefficients for the new variables represent the effect of each category compared to a reference category. In each case, the reference category chosen was the category least likely to complete degrees. This choice was made on the basis of preliminary descriptive statistics examined by the second author.

In both analyses, the regression equation was built with forward. stepwise entry, using the computationally more intensive likelihood-ratio (LR) test, rather than the Wald statistic, as the criterion for determining variables to be removed from the model (Hauck \& Donner. 1977; Jennings, 1986). Stepwise regression provides a useful and effective means of studying outcomes which have received little prior attention or are unknown (Draper \& Smith, 1981). $\underline{\mathrm{P}}$-in was set at 0.05 and $\mathrm{p}$-out at 0.10 in order to identify as many possible associations to retention as possible.

Following Hosmer and Lemeshow (1989), the following procedure was utilized for selection of significant independent variables and interactions: (1) Stepwise selection of main effects; (2) forced entry of the main effects significant on step (1), followed by stepwise selection of interaction terms given the main effects variables in the model; and (3) assessment of the final model through examination of goodness-of-fit statistics. 


\section{Results}

\section{Sample Characteristics}

Sample characteristics are presented in Table 1 for the 698 graduate students in the identification sample, disaggregated by level of study and selected demographic and academic independent variables.

As can be seen, females are somewhat more likely than males to earn their degrees at both levels. At the master's and doctoral levels, males are more likely than females to be withdrawn by the university while, at the doctoral level. females are more likely to leave the program voluntarily. Full-time students

\section{Table 1}

Percentage of Graduated and Withdrawn Students by Level and Selected Demographic and Academic Independent Variables

\begin{tabular}{|c|c|c|c|c|c|c|}
\hline$\underline{\mathrm{N}}$ & $\%$ & $\%$ & COMPARISON & $\underline{N}$ & $\%$ & $\%$ \\
\hline & Graduated & Fithdrawn & VARIABLE & & Graduated & ithdrawn \\
\hline & & & SEX & & & \\
\hline 338 & 71.6 & 28.4 & Male & 99 & 48.5 & 16.2 \\
\hline 201 & 76.1 & 23.9 & Female & 60 & 51.7 & 48.3 \\
\hline
\end{tabular}

$\begin{array}{rrrrrrr}400 & 79.3 & 20.7 & \mathrm{~F} / \mathrm{T} & 139 & 53.2 & 46.8 \\ 139 & 56.1 & 43.9 & \mathrm{P} / \mathrm{T} & 20 & 25.0 & 75.0\end{array}$

\begin{tabular}{ccccccc}
\multicolumn{7}{c}{ PROGRAM TYPE } \\
267 & 68.5 & 31.5 & Course & - & - & - \\
130 & 87.7 & 12.3 & MRP & - & - & - \\
141 & 69.5 & 30.5 & Thesis & 159 & 49.7 & 50.3
\end{tabular}

\section{DISCIPLINE AREA}

\begin{tabular}{lllcrll}
110 & 75.5 & 24.5 & Natural Science & 19 & 78.9 & 21.1 \\
259 & 72.6 & 27.4 & Social Science & 97 & 49.5 & 50.5 \\
170 & 72.9 & 27.1 & Humanities & 43 & 37.2 & 62.8 \\
\hline 539 & 73.3 & 26.7 & TOTAL & 159 & 49.7 & 50.3 \\
\hline
\end{tabular}


fare significantly better than part-time students in earning their degrees at both levels. At the master's level, students who chose coursework plus a major research paper were most likely to complete their degrees, while about one-third of those choosing coursework only or coursework plus a thesis left the university. Students from the natural sciences, social sciences and humanities were equally likely to complete their master's degrees; however, half of all students enrolled in the social sciences and two-thirds of those enrolled in the humanities failed to earn their doctorates.

A total of $32 \%$ of students failed to complete their graduate degrees at this university. Although an attempt was made to determine the cause of withdrawal identified for each student, there is an inherent confound in the distinction of voluntary versus obligatory or mandatory withdrawals. Students who perform poorly may be counselled by their colleagues to withdraw voluntarily in good standing to avoid having their transcripts marred by a forced withdrawal due to academic failure or failure to respond to time requirements. Students withdrawn by the university for failure to maintain registration may have voluntarily left to pursue other alternatives without notifying the university administrator.

Keeping the above in mind, $24 \%$ of withdrawing students for whom data were available were identified as voluntary withdrawals; they most often cited employment, followed by personal and financial difficulties, as reasons for withdrawal. Approximately $14 \%$ of students indicated that they were dissatisfied and/or were transferring to another university. Another $8 \%$ of students were clearly identified as withdrawn by the university for failure to maintain continuous registration, failure to maintain academic standards, or failure to complete degree requirements within specified time limits.

\section{Logistic Regression Analysis of Master's Student Retention}

Results of the logistic regression analysis for master's students are presented in Table 2.

The interpretation of the logistic coefficient is more difficult than in the case of multiple linear regression and, as a result. instead of the conventional Beta coefficient, the logistic model is rewritten in terms of the odds of an event occurring, defined as the ratio of the probability that an event will occur to the probability that it will not. Factors with values greater than one indicate that the odds are increased; and those with values less than one indicate that the odds are decreased (SPSS, 1989).

Of the 21 independent variables available to the regression solution, only four bear a statistically significant relationship to the prediction of retention at the master's level. None of the interaction terms met the criterion for inclusion 
Table 2

Logistic Regression of Student Retention at the Master's Level

Wald

Variable

Statistic

Significance

Odds

Length of Time

in Program

.0000

2.88

Graduate GPA

18.54

.0000

2.12

Average Funds

(All Sources Combined)

10.32

.0013

5.00

Type of Study

19.42

.0016

F/T - Coursework

5.69

.0171

F/T - Major Paper

9.89

.0017

30.97

$\mathrm{F} / \mathrm{T}$ - Thesis

1.23

.2682

108.35

$\mathrm{P} / \mathrm{T}$ - Coursework

7.53

.0061

4.64

P/T - Major Paper

3.26

.0709

46.64

13.64

in the logistic regression model. The length of time spent by the student in the graduate program entered the model first. The value for the odds of this variable indicates that, as the length of time in the program increases, the odds of graduating with a master's degree increase by a factor of 2.88 . The student's graduate GPA also contributes to the prediction of retention; as graduate GPA rises, the odds of completing the degree increase by a factor of 2.12 . The average amount of funding received by the student from all sources further contributes to the prediction of retention. As was the case with length of time in the program and graduate GPA, the odds of completing the degree increase as the value of funding rises.

Finally, the type of study variable provides very interesting results. As shown in Table 2, five separate contrasts were examined. Each of these contrasts is evaluated against the reference category of part-time registration status/thesis type of study, which was the category of student least likely to complete a master's degree. Two components of this variable, the full-time/thesis and part-time/major research paper options, are nonsignificant at the .05 level. This indicates that, relative to being part-time and doing a thesis, neither 
of these alternatives increases the chances of graduating with the master's degree. The full-time/major research paper option and the part-time/coursework only option do increase the odds of graduating and by a substantial amount. The odds of a full-time student doing a major research paper graduating are increased by a factor of 108.35 relative to being enrolled part-time and doing a thesis. The odds of a student enrolled part-time doing the coursework only option graduating are increased by a factor of 46.64 . Finally, the result for the full-time/coursework only option indicates that enrollment in this type of study increases the odds of completing the degree by a factor of 30.97 relative to being part-time and doing a thesis.

One means of assessing how well the logistic model performs is to compare the predictions made by the model to observed outcomes in the data. The classification table for the calibration and validation samples of master's students displayed in Table 3 provides a measure of the discriminative efficiency of the logistic regression model.

Table 3 indicates that the logistic regression model containing the four significant variables successfully classifies the majority of students in both samples. Roughly $9.7 \%$ (23) of those in the calibration sample who are predicted to graduate (203) actually fail to do so, while $2.5 \%$ (6) of those predicted to leave

Table 3

Classification Table of Predicted vs. Observed Outcomes of the Logistic Regression Model for Master's Students

\section{Predicted Outcome}

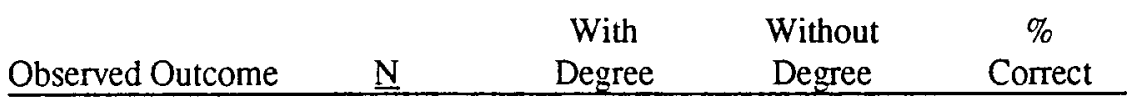

Calibration Sample

With Degree

Without Degree
237

180

23

35

240

\begin{tabular}{rr}
6 & 96.77 \\
28 & 54.90 \\
\cline { 2 - 2 } Overall & 87.76
\end{tabular}

Validation Sample

With Degree

Without Degree

\begin{tabular}{rr}
11 & 94.27 \\
13 & 27.08 \\
\cline { 2 - 2 } Overall & 80.83
\end{tabular}


Table 4

Logistic Regression of Student Retention at the Doctoral Level

\begin{tabular}{lccc} 
Variable & $\begin{array}{c}\text { Wald } \\
\text { Statistic }\end{array}$ & Significance & Odds \\
\hline $\begin{array}{l}\text { Length of Time } \\
\text { in Program }\end{array}$ & 11.39 & .0007 & 1.91 \\
$\begin{array}{l}\text { Average Funds } \\
\quad \text { (All Sources Combined) }\end{array}$ & 6.54 & .0105 & 2.94 \\
\hline
\end{tabular}

the university before completing their degrees (34) actually persist to graduation. In the validation sample, these figures are $14.5 \%$ (35) and $4.5 \%$ (11), respectively. Overall. the logistic model correctly classifies $87.76 \%$ of master's students in the calibration sample and $80.83 \%$ in the validation sample. Note that, relative to the validation sample, cases are somewhat better classified in the calibration sample. This is to be expected when a model is increasingly fine-tuned according to cases in the calibration sample; classification of cases in the validation sample deteriorates because the more precision the model has, the greater the effect discrepant cases have on the overall prediction rate.

\section{Logistic Regression Analysis of Doctoral Student Retention}

The results obtained from the logistic regression analysis for doctoral students must be interpreted with some degree of caution because of the relatively small sample size (62) to predictor (21) ratio. The use of separate calibration and validation samples, however, lends considerable support to the present findings.

Table 4 displays the results of the analysis. Only two of the independent variables available to the regression solution significantly contribute to the prediction of retention.

The length of time spent in the graduate program and the average amount of funding received from all sources add significantly to the explanation of retention at the doctoral level. The former nearly doubles and the latter almost triples the odds of graduating with the doctorate. As the length of time in the program increases, so do the odds of completing the doctorate. As the amount of funding received from all sources increases, the odds of successfully completing all degree requirements also rise. 
Classification of the observed versus predicted values of the logistic regression solution for doctoral students is shown in Table 5. Examination of this table reveals that, in the calibration sample, 9.7\% (6) of those predicted to earn degrees (31) fail to do so, while an equal percentage of those predicted to withdraw before completing their doctorates actually persist to degree conferral. In the validation sample, the percentages are $11.0 \%$ (7) for both false positives and false negatives. The logistic model for doctoral students correctly classifies $80.7 \%$ of the calibration sample and somewhat less, $77.4 \%$, of the validation sample.

\section{Discussion}

Logistic regression was used to formulate two empirical models describing the retention pattems of graduate students. The separate models generated for master's and doctoral students are discussed below.

\section{Retention at the Master's Level}

Of the 21 independent variables and three possible interaction terms available to the logistic regression solution, only four variables were significantly related to

Table 5

Classification Table of Predicted vs. Observed Outcomes of the Logistic Regression Model for Doctoral Students

\begin{tabular}{|c|c|c|c|c|}
\hline \multirow[b]{2}{*}{ Observed Outcome } & \multicolumn{4}{|c|}{ Predicted Outcome } \\
\hline & $\underline{N}$ & $\begin{array}{l}\text { With } \\
\text { Degree }\end{array}$ & $\begin{array}{l}\text { Without } \\
\text { Degree }\end{array}$ & $\begin{array}{c}\% \\
\text { Correct }\end{array}$ \\
\hline
\end{tabular}

Calibration Sample

With Degree

Without Degree

Validation Sample

With Degree

Without Degree
62

\begin{tabular}{rrr}
25 & 6 & 80.65 \\
6 & 25 & 80.65 \\
\hline Overall & 80.65
\end{tabular}

62

\begin{tabular}{rrr}
26 & 7 & 78.79 \\
7 & 22 & 75.86 \\
\hline & Overall & 77.42
\end{tabular}


retention at the master's level: length of time in the program, graduate GPA, average amount of funding and type of program.

The length of time spent in the program was the single most important contributor to the model of retention at the master's level. Students who remained in the program longer were more likely to graduate than were those who did not remain in so long. This finding is not surprising, since graduated master's students spend, on average, longer in the program (2.74 years) than either those who withdraw voluntarily (1.39 years) or those who are withdrawn by the university (1.47 years) (Sheridan, 1990). This variable indicates that, regardless of graduate GPA or funding, the longer one remains in the program, on average, the more likely one is to complete the degree.

The student's graduate GPA was also a significant predictor of retention at the master's level. This confirms the findings of Girves and Wemmerus (1988), who reported that graduate grades were the best predictor of degree progress at the master's level. Undergraduate GPA was not a significant variable in prediction of success at this level.

Although the present finding is contrary to the common assumption that grades at the graduate level are too homogeneous to provide predictive power to an attrition equation, this result is not surprising. Assuming that graduate grades are reflective of ability, this finding indicates that students of apparently higher ability are more likely to complete their degrees than those of comparatively lower ability. Although higher ability students are typically those who receive greater amounts of funding, the influence of graduate grades on attrition does not reflect the partial contribution of financial effects, since regression procedures control for this potential confound by partialling out the contributions of included third variables. Girves and Wemmerus (1988) suggest that the effect of grades at the graduate level is to increase involvement in the program, which increases academic integration, leading the student to be more committed to the goal of earning the degree.

The average amount of funding received from all sources was also a significant predictor of successful degree completion at the master's level. Many researchers (Berg \& Ferber, 1983; Dolph, 1983; Girves \& Wemmerus, 1988; Patterson \& Sells, 1973) have indicated that financial aid is positively correlated with increased retention at the graduate level. The forms of financial aid provided for master's students in this study are usually RAs, GAs, or TAs (rather than grants or fellowships). These types of employment are more likely to bring the student into contact with other students and faculty, which results in greater involvement in the program and potentially increased commitment to the goal 
of earning a degree. Furthermore, it relieves the student from engaging in employment outside the university, which might deflect the student from academic pursuits to a greater extent than employment within the university setting (Astin. 1975; Fields \& Lemay, 1973; Iffert, 1957).

Finally, the type of program variable was significant at the master's level. This term provided a substantial increase in explanatory power over other empirical models of retention which were considered (Sheridan, 1990). Students enrolled on a full- or part-time basis in the coursework only option are significantly more likely to complete their degrees than those enrolled part-time in the coursework plus thesis option. Students enrolled full-time in the coursework plus major research paper option are overwhelmingly more likely to earn their master's degrees than those enrolled part-time in the coursework plus thesis option. Finally, students enrolled full-time doing a thesis and students enrolled part-time doing a major research paper are not significantly more likely to complete their degrees than are those enrolled part-time doing a thesis.

These data offer partial support to the results of other researchers who have found that full-time master"s students earn degrees with a significantly higher frequency than those enrolled part-time (Girves \& Wemmerus, 1988; Ott \& Markewich, 1985; Ott et al., 1984; Pyke, 1990). In addition, the results partially support the notion that programs requiring a thesis have a significantly higher dropout rate than those requiring coursework only, but qualify an extremely important interaction between registration status and type of program. Registration status is not a significant contributor to attrition if a student is enrolled in a coursework plus thesis course of study. Similarly, the type of program a part-time student chooses appears only to improve retention if it is the coursework only option. While Ott and Markewich (1985) found that registration status was the primary factor associated with retention and degree progress of graduate students, this generalization would seem to require qualification at least for the master's students in this sample.

The identification of the type of study variable is particularly relevant to curriculum decisions. Whether a student is enrolled part-or full-time, the coursework plus thesis option appears to be troublesome in the retention of graduate students at the master's level. It would further appear that part-time students doing a major research paper also face significant impediments to successful degree completion. If graduate degree achievement is the criterion by which one evaluates the effectiveness of a graduate program, a coursework only model is the most successful curriculum delivery format for part-time students. 


\section{Retention at the Doctoral Level}

Only two variables are significant in the final logistic regression solution predicting successful degree completion at the doctoral level; one of these is a financial variable, the average amount of funding received from all sources, and the other is the length of time spent in the program.

Many authors have reported that financial support is positively related to retention at the doctoral level (Dolph, 1983; Girves \& Wemmerus, 1988; Patterson \& Sells, 1973). Girves and Wemmerus speculate that receipt of financial support at this level allows students to become more involved in their graduate programs, which leads to an increased chance of completing the degree. They speculate that students who receive financial support in the form of RAs, TAs, or fellowships are more likely to become integrated into the program because such students work closely with the teaching and research team, have a greater opportunity to make faculty contacts, and become socialized into the department (cf. Rodriguez, 1984). Because they are free from the hassles and worries of outside employment, students receiving financial aid are more likely to become involved in their programs, which, in turn, increases their motivation and commitment towards earning the doctorate. Thus, provision of increased financial support should facilitate a student's successful completion of the doctoral degree.

The length of time spent in the program is also significantly related to retention at the doctoral level. As the length of time spent in the program increases, the odds of graduating with the degree, as one would expect, also increase. This variable is the most significant predictor of student retention at the doctoral level. Earning a degree is inherently time-consuming; the withdrawal alternatives are, on average, less so. Some students probably receive high amounts of funding early on and complete their degrees relatively quickly. Other students receive less financial support but compensate by remaining in the program for longer durations. Presumably, the more financially advantaged a graduate student is, the easier it becomes for him or her to devote him/herself to the academic tasks at hand and to complete all degree requirements successfully.

Having higher grades at the graduate level increased a student's chance of earning a master's, but the effects of grades disappear at the doctoral level (cf. Girves \& Wemmerus, 1988). Perhaps this is due to the relative importance of graded course requirements at the master's level which decrease at the Ph.D. level, where independent study and dissertation research are accorded greater importance; or to the fact that Ph.D. candidates represent a more restricted 
range of academic abilities than do master's candidates. Undergraduate grades were not significantly related to student retention at the doctoral level, as was also the case at the master's level.

Evaluation of these models by examining the goodness-of-fit statistics and the classification tables indicates that these models fit the data well (better in the case of master's than doctoral candidates, likely because of the larger number of master's students). Another means of assessing these predictive models is to determine the uncertainty reduction in the prediction of degree completion at each level.

For the 477 master's students included in the logistic regression procedure, 361 of those who were predicted to complete their degrees actually did so, and 41 of those who were predicted to fail to complete their degrees also performed as predicted. This represents an $84.3 \%$ classification rate for candidates at the master's level. Only $73.3 \%$ of master's students did successfully complete their degrees at York University. Thus, predicting student retention at the master's level on the basis of the empirically generated model improves prediction by approximately $11.0 \%$.

At the doctoral level, only $49.7 \%$ of students actually successfully completed their degrees. Utilizing the model for doctoral candidates, 51 of those students predicted to complete did so and 47 of those predicted to fail to earn their degrees did fail to do so. This represents a successful classification rate of approximately $79.0 \%$ for doctoral candidates. Predicting student retention at the doctoral level on the basis of the model increases the obtained results by $29.3 \%$.

Unfortunately, the models of master's and doctoral student retention presented here are of little use in selecting at the admission stages those candidates who will successfully complete their degrees. Although one of the goals of the study was to provide a set of criteria in the form of a predictive equation which could be utilized at the point of admission to select better those students who would eventually complete their degrees, only one pre-entry attribute (type of study) was significant in the logistic regression solution for master's students, and none was significant in the solution for doctoral students. This supports the near-universal conclusion of researchers at the undergraduate level that pre-entry attributes either do not significantly influence persistence and withdrawal (Bean, 1980, 1982; Pascarella \& Terenzini, 1979; Terenzini \& Pascarella, 1977, 1978) or are only minimally predictive of attrition from higher education (Pascarella, Duby, Miller \& Rasher, 1981). It also supports the notion that what happens to a student once enrolled in graduate education appears to be far more relevant in terms of predicting attrition than prior history. 


\section{Summary and Implications}

For master's students, higher graduate GPAs, increased length of time in the program. increased funding from all sources, full- or part-time registration status in the coursework only option. and full-time registration status in the coursework plus major research paper option significantly improve the chances of graduating with the degree.

For doctoral candidates, only increased length of time in the program and increased funding from all sources significantly increase the chances of graduating with the doctorate. Of course, a number of other factors not included in this investigation may have significant influence on attrition. Unfavourable economic conditions may enhance retention while very attractive employment opportunities may encourage attrition. The latter is reputed to be an important determinant of attrition from graduate programs in engineering, for example. This discipline was not represented in the present study and the archival methodology precluded analysis of an economic opportunity variable. As noted earlier, a sizable proportion of students did cite employment as their reason for withdrawal.

Although the results of the present study were derived from the performance of graduate students at one university, the findings are not peculiar to this institution. Fletcher and Stren (1992), for example, surveyed recent and current doctoral students at the University of Toronto using a very different methodology and found that financial factors were the most important impediments to success in doctoral programs at that university. The authors reported dramatic differences between the physical and life science disciplines and the humanities and social science disciplines in financial support received by students. Once such differences were statistically controlled for, the success of students across disciplines was essentially equivalent.

The present data indicate that predictors of graduate student retention can be identified. The prediction of retention is of considerable importance. Costs to the individual, the program, and the university are substantial, especially since decisions to drop out (or decisions on the part of the university to dismiss a student) often come after several years of study at the graduate level. The results of this investigation suggest that curriculum choices (most importantly, decisions regarding the implementation of optional program formats), selection procedures (especially of students applying for admission to part-time studies) and rigorous attempts at securing adequate financial resources for students be given careful consideration by individual programs as well as by the university 
administration. Supervisors and university guidance personnel would be well advised to consider some of the present findings when dealing directly with the graduate student population.

\section{References}

Association of Universities and Colleges of Canada. (1991). Averting faculty shortages: A discussion paper on the Canadian acadenic labour market in the 1990s. Ottawa: Author.

Astin, A. W. (1975). Preventing students from dropping out. San Francisco: Jossey-Bass.

Bean, J. P. (1980). Dropouts and turnover: The synthesis and test of a causal model of student attrition. Research in Higher Education, 12, 155-187.

Bean, J. P. (1982). Student attrition. intentions, and confidence: Interaction effects in a path model. Research in Higher Education, 17, 291-320.

Berg, H. M. \& Ferber, M. A. (1983). Men and women graduate students: Who succeeds and why? Journal of Higher Education, 54, 629-648.

Calder, W. B., McKay, B., \& Nelson, R. Student withdrawal: A developmental perspective. (1977). Waterloo: Wilfrid Laurier University Press.

Cope. R. G. \& Hannah. W. (1975). Revolving college doors: The causes and consequences of dropping out, stopping out, and transferring. New York: Wiley.

Dolph. R. F. (1983). Factors relating to success or failure in obtaining the doctorate. Unpublished doctoral dissertation, Georgia State University, Georgia.

Draper, N. R. \& Smith. H. (1981). Applied regression analysis (2nd ed.). New York: John Wiley \& Sons.

Duggan. J. J. (1989). Time to the doctoral degree and success rates: The Berkeley experience. Unpublished data. Berkeley: University of California at Berkeley.

El-Khawas, E. (1987). Campus trends 1987. Washington, D.C.: American Council on Education.

Fields. C. R. \& LeMay, M. L. (1973). Student financial aid: Effects of educational decisions and academic achievement. Journal of College Student Personnel, 14. 425-429.

Fletcher, J. \& Stren, R. (February, 1992). Report on a survey of recent and current doctoral students at the University of Toronto. Paper presented at the Council of Ontario Universities/Ontario Council on Graduate Studies Colloquium. Toronto, Ontario.

Girves. J. E. \& Wemmerus, V. (1988). Developing models of graduate student degree progress. Journal of Higher Education, 59, 163-189.

Hauck, W. W. \& Donner, A. (1977). Wald's test as applied to hypotheses in logit analysis. Journal of the American Statistical Association, 72, 851-853.

Hosmer. D. W., Jr. \& Lemeshow, S. (1989). Applied logistic regression. New York: John Wiley \& Sons.

Iffert, R. E. (1957). Retention and withdrawal of college students (Bulletin 1958, \#1). Washington, D. C.: U. S. Government Printing Office.

Jennings. D. E. (1986). Judging inference adequacy in logistic regression. Journal of the American Statistical Association, 81, 471-476. 
Kerlinger, F. \& Pedhazur, E. (1973). Multiple regression in behavioral research. New York: Holt.

Lewis-Beck, M. S. (1980). Applied regression: An introduction. Quantitative Applications in the Social Sciences, 22, 5-79.

Malaney, G. D. (1984). An analysis of financial aid in recruitment of graduate students at Ohio State University. Journal of Student Financial Aid, 14, 11-19.

Munro, B. H. (1981). Dropouts from higher education: Path analysis of a national sample. American Educational Research Journal, 18, 133-141.

Naylor, P. D. \& Sanford, T. R. (1982). Intrainstitutional analysis of student retention across student levels. College and University, 57, 143-159.

Ott, M. D. \& Markewich, T. S. (1985). Logit analysis and graduate student retention and graduation. Paper presented at the 1985 AIR Forum, Portland, Oregon.

Ott, M. D.. Markewich, T. S. \& Ochsner, N. L. (1984): Logit analysis of graduate student retention. Research in Higher Education, 21, 439-460.

Pantages, T. J. \& Creedon, C. F. (1978). Studies of college attrition: 1950-1975. Review of Educational Research, 48, 49-101.

Pascal, C. E. \& Kanowitch, S. (1979). Student withdrawals from Canadian universities: A study of studies. Toronto, Ontario, Canada: The Ontario Institute for Studies in Education, Higher Education Group.

Pascarella, E. T. \& Chapman. D. W. (1983). A multiinstitutional, path analytic validation of Tinto's model of college withdrawal. American Educational Research Journal, 20,87-102.

Pascarella, E. T., Duby, P. B., Miller, V. A. \& Rasher, S. P. (1981). Pre-enrollment variables and academic performance as predictors of freshman year persistence, early withdrawal, and stopout behaviour in an urban, nonresidential university. Research in Higher Education, 15, 329-349.

Pascarella, E. T. \& Terenzini, P. T. (1979). Interaction effects in Spady's and Tinto's conceptual models of college dropout. Sociology of Education, 52, 197-210.

Pascarella, E. T. \& Terenzini, P. T. (1983). Predicting voluntary freshman year persistence/withdrawal behaviour in a residential university: A path analytic validation of Tinto's model. Journal of Educational Psychology, 75, 215-226.

Patterson, M. \& Sells. L. (1973). Women dropouts from higher education. In A. S. Rossi \& A. Calderwood (Eds.), Academic women on the move. New York: Russel Sage Foundation.

Pyke, S. W. (1990). Withdrawal rates, graduation rates, and time to completion for master's students. Unpublished manuscript. York University, Faculty of Graduate Studies and Department of Psychology, North York, Ontario, Canada.

Rodriguez, J. E. (1984). Faculty mentoring of minority graduate and professional students: The Irvine experiment. Irvine: University of California at Irvine, Division of Graduate Studies and Research.

Rogers, B. H. \& Gentemann. K. M. (1989). The value of institutional research in the assessment of institutional effectiveness. Research in Higher Education, 30, 345355. 
Sheinin, R. (1989). Review of the implementations of the recommendations of the Report on the "Status of Women in Ontario Universities." In C. Filteau (Ed.), Proceedings of a conference of women in graduate studies in Ontario. Toronto, Ontario, Canada: Ontario Council on Graduate Studies.

Sheridan, P. M. (1990). Effects of demographic, academic and financial variables on graduate-student persistence, withdrawal and degree progress at York University. Unpublished master's thesis, York University, North York. Ontario, Canada.

SPSS. (1989). SPSS/PC + update for V3.0 and V3.1. Chicago: Author.

Stage, F. K. (1989a). University attrition: LISREL with logistic regression for the persistence criterion. Research in Higher Education, 29, 343-357.

Stage. F. K. (1989b). Reciprocal effects between the academic and social integration of college students. Research in Higher Education, 30, 517-530.

Terenzini, P. T. \& Pascarella. E. T. (1977). Voluntary freshman attrition and patterns of social and academic integration in a university: A test of a conceptual model. Research in Higher Education, 6, 25-43.

Terenzini, P. T. \& Pascarella, E. T. (1978). The relation of students' precollege characteristics and freshman year experience to voluntary attrition. Research in Higher Education, 9, 347-366.

Tinto. V. (1975). Dropouts from higher education: A theoretical synthesis of recent research. Review of Educational Research, 45, 89-125.

Tinto, V. (1987). Leaving college: Rethinking the causes and cures of student attrition. Chicago: University of Chicago Press.

Tuckman, H. P., Coyle, S. \& Bae, Y. (1989). The lengthening of time to completion of the doctorate degree. Research in Higher Education, 30, 503-516.

Tuckman. H. P., Coyle, S. \& Bae, Y. (1990). On time to the doctorate. Washington: National Academy Press. 